Evan D. Kharasch MD PhD, ${ }^{*}$ Kiang-Teck Yeo PhD, $\dagger$ Margaret A. Kenny PhD, *† David W. Amory MD PhD*

\title{
Influence of hypother- mic cardiopulmonary bypass on atrial natriuretic factor levels
}

Atrial natriuretic factor (ANF) is a peptide released from the heart in response to atrial distension. This peptide causes diuresis, vasodilatation, decreased blood pressure, and antagonizes the renin-aldosterone and antidiuretic hormone neuraxes. The influence of cardiopulmonary bypass and cardiac surgery on the circulation and release of ANF is unknown. Plasma ANF concentrations were therefore determined in patients undergoing coronary artery revascularization ( $C A B G$ ) and mitral valve replacement (MVR). Peptide levels were unchanged following anaesthetic induction. Plasma ANF concentrations decreased significantly during hypothermic $\left(\leq 28^{\circ} \mathrm{C}\right)$ cardiopulmonary bypass in both patient groups. After 60 minutes of cardiac bypass, ANF declined from (mean \pm SEM) $512 \pm 132$ to $20 \pm 6$ $p g \cdot \mathrm{ml}^{-1}(P<0.05)$ during $M V R$, and from $178 \pm 41$ to $110 \pm$ $48 \mathrm{pg} \cdot \mathrm{ml}^{-1}$ during $C A B G(P<0.05)$. Rewarming during bypass was associated with an increase in ANF concentration in both groups. Heparin anticoagulation and protamine reversal had no effect on immunoreactive ANF levels. In patients undergoing $C A B G$, there was a linear relationship between plasma ANF concentration ( $\mathrm{pg} \cdot \mathrm{ml}^{-1}$ ) and right atrial pressure $(\mathrm{mmHg})$ prior to cardiopulmonary bypass $(r=0.86, P<$ $0.005)$. However, one and three hours after cardiopulmonary bypass there was no significant relationship between right atrial pressure and ANF plasma levels. These results suggest that

\section{Key words}

ANAESTHESIA: cardiovascular; ANAESTHETIC TECHNIQUES: cardiopulmonary bypass; HEART: myocardial function; HORMONES: atrial natriuretic factor.

From the Departments of Anesthesiology* and Laboratory Medicine, $\dagger$ University of Washington School of Medicine, Seattle, Washington.

Supported by USPHS grant GM 07604 to the Department of Anesthesiology. Presented in part at the New York State Society of Anesthesiologists' Postgraduate Assembly, December 12-16, 1987.

Address correspondence to: Dr. Evan D. Kharasch, Department of Anesthesiology RN-10, University of Washington, Seattle, WA 98195. reduction in plasma ANF concentration occurs during hypothermic cardiopulmonary bypass. Furthermore, the proportional relationship between atrial distension and circulating ANF concentration was altered following cardiac surgery.

Since the seminal observation by de Bold and coworkers that secretory granules in cardiac atria contain a substance with natriuretic activity, ${ }^{1}$ the role of the heart as an endocrine organ has been firmly established. ${ }^{2,3}$ Cardiac atria synthesize, store, and secrete via the coronary sinus a 28 amino acid hormone, termed atrial natriuretic factor (ANF), which manifests renal, vasomotor, and cardiovascular effects. Atrial natriuretic factor produces a dosedependent increase in urine volume and electrolyte excretion, primarily by increasing glomerular filtration rate. ${ }^{2-4}$ The peptide also antagonizes the vascular and saline-conserving effects of the renin-angiotensin-aldosterone system and antidiuretic hormone (ADH). Atrial natriuretic factor inhibits renin release, decreases plasma renin activity, inhibits aldosterone synthesis, and antagonizes the end-organ effects of angiotensin II. $^{3,5-7}$ It also inhibits pituitary ADH secretion, lowers circulating ADH levels, and may antagonize the renal tubular effects of $\mathrm{ADH} .^{8,9}$ As a potent vasodilator, ANF elicits renal artery dilatation and decreases systemic blood pressure. ${ }^{2,5,7}$ Finally, ANF release in response to volume expansion is the efferent limb of an autoregulatory feedback mechanism in which cardiac preload is decreased by reducing intravascular volume. ${ }^{5,7}$ The rapid modulation of ANF release in response to changes in vascular volume and right atrial pressure, ${ }^{10}$ and the short elimination half-life (2-3 min) of ANF, ${ }^{11}$ suggest a role in minute to minute regulation of fluid and electrolyte balance.

Atrial distension is the major stimulus for ANF secretion. Distension of either atrium elicits peptide release, ${ }^{12,13}$ although some evidence suggests a greater contribution from the right atrium. ${ }^{14}$ Increased atrial pressure stimulates proportional ANF release. In addition, a linear relationship between plasma ANF concentration and both right atrial pressure and pulmonary capillary wedge pressure has been demonstrated. ${ }^{12,13}$ 
Plasma ANF levels have also been correlated with atrial size. $^{13,15}$ Atrial temperature and frequency of atrial distension affect peptide release, ${ }^{16,17}$ and circulating ANF levels are proportional to heart rate. ${ }^{18,19}$ However, atrial contraction is not required for stretch-induced ANF release. In nonbeating atria passive stretch provides the stimulus for hormone release. ${ }^{16}$ Thus heart rate, atrial size, atrial pressure, atrial wall tension and temperature mediate the release of ANF.

Cardiopulmonary bypass (CPB) and cardioplegiainduced cardiac arrest decrease atrial pressure, stretch, and contraction. Since these are the stimuli for ANF release, CPB may diminish release of ANF. In addition, ANF secreted during $C P B$ may be delayed in reaching the systemic circulation because of diminished coronary sinus and atrial blood flow. Thus we have examined the influence of hypothermic CPB and cardioplegic arrest during coronary artery revascularization and valve replacement surgery on patterns of release and circulating levels of ANF.

\section{Methods}

\section{Clinical protocol}

Sixteen patients (nine men and seven women) aged 31-80 scheduled for elective cardiac surgery were studied after informed consent was obtained. The study protocol was approved by the institutional human subjects committee. Nine patients underwent coronary artery revascularization (CABG) and seven underwent mitral valve replacement (MVR). Table I provides a description of the patients. Patients were premedicated with benzodiazepines; morphine premedication was avoided since morphine elevated ANF levels in rats ${ }^{20}$ and effects on ANF release in humans were unknown. Intravenous, radial artery, and balloon-tipped thermodilution pulmonary antery catheters were placed. Anaesthesia was achieved with narcotics (fentanyl or sufentanil, benzodiazepines (diazepam or midazolam) and muscle relaxants (pancuronium or vecuronium), supplemented with enflurane.

The vena cava was cannulated via the right atrium with a single Bard two-stage cannula (CABG) or dual superior and inferior cannulae (MVR). Cardiopulmonary bypass utilized a nonpulsatile Sarns roller pump and Bently disposable bubble oxygenator $(n=13)$ or Cobe membrane oxygenator ( $n=3$ ) primed with Ringer's lactate ( 20 $\left.\mathrm{ml} \cdot \mathrm{kg}^{-1}\right)$ and 20 per cent mannitol $\left(5 \mathrm{ml} \cdot \mathrm{kg}^{-1}\right)$ at flow rates of 2.4 (normothermic) or 1.8 (hypothermic) $L$. $\min ^{-1} \cdot \mathrm{m}^{2}$. For MVR deliberate hypothermia commenced coincident with initiation of CPB and was followed immediately by aortic cross-clamping and cardioplegic arrest. For CABG proximal saphenous vein graft anastamoses were performed during normothermic CPB using
TABLE I Patient description and haemodynamic data

\begin{tabular}{lcc}
\hline & $\begin{array}{c}C A B G \\
(n=9)\end{array}$ & $\begin{array}{l}M V R \\
(n=7)\end{array}$ \\
\hline Mean age (range) & $67(57-80)$ & $51(31-68)$ \\
Sex (M/F) & $7 / 2$ & $2 / 5$ \\
Diagnosis (no. of patients) & & \\
$\quad$ coronary artery disease & 9 & 1 \\
mitral valve disease & 1 & 7 \\
pulmonary hypertension & 0 & 5 \\
Preinduction haemodynamics* & & \\
HR (min ${ }^{-1}$ ) & $65 \pm 3$ & $84 \pm 4 \dagger$ \\
MAP (mmHg) & $98 \pm 3$ & $90 \pm 4$ \\
RAP (mmHg) & $10.0 \pm 1.8$ & $10.0 \pm 2.0$ \\
MPA (mmHg) & $19 \pm 1$ & $47 \pm 6 \ddagger$ \\
PCWP (mmHg) & $12 \pm 1$ & $29 \pm 4 \ddagger$ \\
CO (L.min ${ }^{-1}$ ) & $4.4 \pm 0.4$ & $4.3 \pm 0.5$ \\
CI (L'min ${ }^{-1} \cdot$ m $^{-2}$ ) & $2.3 \pm 0.2$ & $2.6 \pm 0.2$ \\
Left ventricular ejection fraction (\%) $\$$ & $60(28-76)$ & $66(52-76)$ \\
Cardiopulmonary bypass duration (min) & $124 \pm 17$ & $89 \pm 11$ \\
Aortic cross-clamp duration (min) & $57 \pm 8$ & $69 \pm 9$ \\
\hline
\end{tabular}

See text for abbreviations. Mean values are shown \pm SEM.

*Determined at the time of monitoring line placement.

tSignificantly different between the two groups $(P<0.01)$. †Significantly different between the two groups $(P<0.005)$. \$Measured at the time of cardiac catheterization by contrast ventriculography. Shown are the mean and (range).

a side-biting aortic clamp (approximately $30 \mathrm{~min}$ ). This was followed by initiation of deliberate hypothermia, aortic cross-clamping, cardioplegic arrest and distal coronary anastamoses. The left ventricle was not vented during CPB. Mean duration of CPB and aortic crossclamp are shown in Table I. Hypothermic hyperkalaemic cardioplegia was employed for myocardial preservation. Management during the post-CPB period was not altered for study purposes. All patients received volume (blood or crystalloid) and vasoactive agents as needed.

Blood samples were obtained for ANF quantitation and haemodynamic variables were recorded at the following times: preinduction baseline following insertion of monitoring catheters, after anaesthetic induction and tracheal intubation; after median sternotomy; 5 min after systemic heparinization (pre CPB); 5, 15, 30 and $60 \mathrm{~min}$ on CPB; after rewarming to $36^{\circ} \mathrm{C}$ prior to separation from $\mathrm{CPB}$; off CPB prior to protamine administration; $10 \mathrm{~min}$ after protamine administration; $60 \mathrm{~min}$ after $\mathrm{CPB}$; at skin closure; and $60 \mathrm{~min}$ after arrival in the Intensive Care Unit. If more than 50 min elapsed between heparinization and onset of CPB, a second pre-CPB ANF sample was obtained prior to $C P B$, and this value substituted in place of the post-heparin sample. Plasma ANF was measured in radial artery blood samples except during CPB when blood was obtained from the venous return circuit of the pump oxygenator. The following haemodynamic variables were recorded: heart rate (HR), mean arterial 


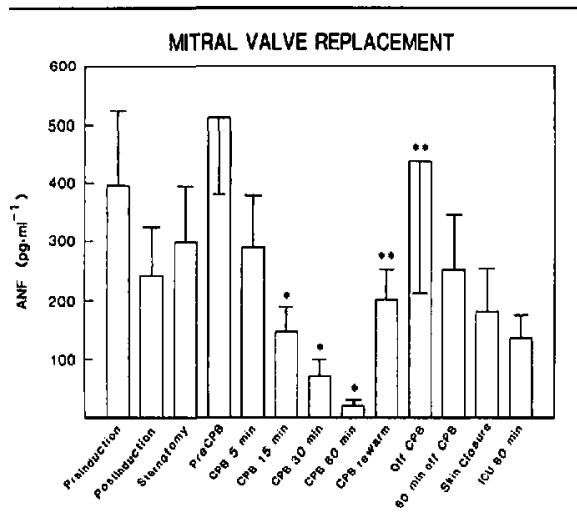

FIGURE 1 Plasma ANF concentrations (mean $\pm S E M$ ) in patients undergoing mitral valve replacement $(n=7)$. Statistical significance in noted as $* P<0.05$ compared with both pre-CPB and CPB 5 min and ${ }^{* *} P<0.05$ compared to CPB 60 min. For the CPB $60 \mathrm{~min}$ sample $n=5$ (see text).

pressure (MAP), pulmonary artery systolic and diastolic pressures (PAS, PAD) mean pulmonary artery pressure (MPA), and pulmonary capillary wedge pressure (PCWP). Mean right atrial pressure (RAP) was measured at end-expiration to within $0.1 \mathrm{mmHg}$. Thermodilution cardiac output (CO) was determined in triplicate. Cardiac index (CI) was calculated from the standard formula. Temperature was measured using an oesophageal thermistor.

\section{Peptide assay}

Blood was collected into chilled polypropylene tubes containing aprotinin ( $\left.500 \mathrm{KIU} \cdot \mathrm{ml}^{-1}\right)$ and disodium EDTA $\left(1 \mathrm{mg} \cdot \mathrm{ml}^{-1}\right)$ and centrifuged at $4^{\circ} \mathrm{C}$. Plasma was immediately frozen in dry ice and stored at $-70^{\circ} \mathrm{C}$ until analyzed. Plasma ANF concentrations were determined within two weeks by radioimmunoassay (RAS-8798, Peninsula Laboratories) following Sep-Pak (Millipore) $\mathrm{C}_{1 \mathrm{~B}}$ extraction. ${ }^{2 \mathrm{I}}$ Sensitivity, inter- and intraassay coefficients of variation were $4 \mathrm{pg} \cdot \mathrm{ml}^{-1}, 19$ and 9 per cent, respectively. Results were corrected for extraction efficiency, which averaged 66 per cent.

Potential interference of heparin or protamine on the radioimmunoassay for ANF was determined in vitro. Approximately $200 \mathrm{pg} \cdot \mathrm{ml}^{-1}$ synthetic ANF (26 amino acid ANF(8-33), L-364, 343)) was added to EDTA and aprotinin-treated human whole blood. This was followed by addition of heparin or heparin plus protamine. Following centrifugation, plasma ANF concentration was determined as described above.

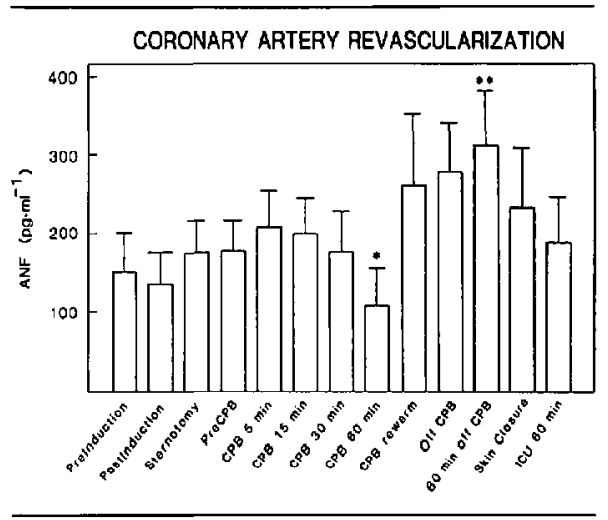

FIGURE 2 Plasma ANF concentrations (mean \pm SEM) during cardiac surgery in patients undergoing coronary artery revascularization $(n=9)$. See legend to Figure 1 for key to symbols.

\section{Statistical analysis}

Data are reported as mean \pm SEM unless otherwise noted. The Mann-Whitney test was employed to compare baseline characteristics of CABG and MVR patients. Differences in ANF concentrations at sampling intervals within a CABG or MVR population were analyzed using Friedman's non-parametric repeated measures analysis of variance, followed by non-parametric Newman-Keuls or Dunnet's tests, where appropriate. ${ }^{22}$ Circulating ANF concentrations before and after heparin and protamine administration were compared using the Wilcoxon paired-sample test. A one-way analysis of variance and Newman-Keuls test were used to compare in vitro effects of heparin or protamine on the radioimmunoassay for ANF, and differences in RAP, PCWP or temperature. Linear regression analysis was performed by the method of least squares. A value of $P<0.05$ was considered significant in all statistical tests.

\section{Results}

Awake baseline operating room plasma ANF concentrations were higher in patients undergoing MVR (396 \pm $124 \mathrm{pg} \cdot \mathrm{ml}^{-1}$ than CABG $\left(151 \pm 52 \mathrm{pg} \cdot \mathrm{ml}^{-1}\right.$ ) (Figures 1 and 2). This was associated with higher heart rates $(P<$ 0.01 ), pulmonary artery pressures (systolic, diastolic and mean; $\boldsymbol{P} \leq 0.005$ for all) and pulmonary capillary wedge pressures $(P<0.005)$ in the MVR patients (Table I). Mean RAP was not significantly different in MVR compared with CABG patients, nor were MAP, CO, CI, or left ventricular ejection fraction.

\section{Influence of $C P B$ on circulating $A N F$ concentration} Plasma ANF levels during mitral valve replacement are 
shown in Figure 1. Peptide concentrations were not significantly different from preinduction values following induction of anaesthesia and initiation of mechanical ventilation, or following median sternotomy. A statistically insignificant increase in mean ANF concentration compared with post-sternotomy values was apparent in the pre-CPB sample. This was due to substantially elevated ANF levels in two patients, associated with the onset of atrial fibrillation following atriotomy and atrial cannulation (not shown). This observation was consistent with the finding that supraventricular tachycardia promotes the release of ANF. ${ }^{23}$ Initiation of CPB was followed by a steady decline in plasma ANF concentration. Peptide levels after $15 \mathrm{~min}\left(145 \pm 48 \mathrm{pg} \cdot \mathrm{ml}^{-1}\right)$ and $30 \mathrm{~min}\left(71 \pm 32 \mathrm{pg} \cdot \mathrm{ml}^{-1}\right)$ of CPB were significantly lower than the pre CPB value $\left(512 \pm 132 \mathrm{pg} \cdot \mathrm{ml}^{-1}\right)$. In two patients, rewarming occurred before $60 \mathrm{~min}$ of CPB. In the remaining five patients, there was a further significant decline in ANF concentration to $20 \pm$ $6 \mathrm{pg} \cdot \mathrm{ml}^{-1}$ after $60 \mathrm{~min}$ of CPB. To control for the effects of haemodilution and different blood sampling sites during CPB, ANF concentration was determined $5 \mathrm{~min}$ after initiation of CPB. Re-analysis of the data using this sample as a control still showed a significant decrease in ANF concentration during CPB. Rewarming to $>36^{\circ} \mathrm{C}$ during $\mathrm{CPB}$ was associated with a marked increase in ANF concentration. Hormone levels were further elevated following separation from CPB. Plasma ANF concentrations declined thereafter, reaching postinduction values by the time of skin closure $\left(176 \pm 79 \mathrm{pg} \cdot \mathrm{ml}^{-1}\right)$, and were further decreased to $136 \pm 36 \mathrm{pg} \cdot \mathrm{ml}^{-1} 60 \mathrm{~min}$ after arrival in the Intensive Care Unit $(169 \pm 12 \mathrm{~min}$ after separation from $\mathrm{CPB}$ ).

Figure 2 depicts plasma ANF concentrations in patients undergoing elective CABG. Hormone levels were unchanged through the initiation of CPB. After $60 \mathrm{~min}$ of CPB there was a 50 per cent decrease in plasma ANF concentration to $110 \pm 47 \mathrm{pg} \cdot \mathrm{ml}^{-1}$, which was statistically significant compared with either the pre CPB or CPB 5 min values. In two patients hypothermic $C P B$ continued longer than $60 \mathrm{~min}$ and an additional blood sample was obtained prior to onset of rewarming. In both patients, a further decline in ANF concentration was observed (data not shown). Rewarming produced a 2.5 -fold increase in ANF concentration, which persisted following separation from CPB. Peptide concentrations declined during the post-CPB period, reaching pre-CPB values by the time of skin closure.

Table II provides haemodynamic and temperature data for both groups during CPB. During MVR deliberate hypothermia was instituted immediately after attaining full CPB, with an attendant immediate decline in oespohageal temperature to $<28^{\circ} \mathrm{C}$. During CABG there occurred only small decreases in temperature until the institution of deliberate hypothermia which occurred after approximately $30 \mathrm{~min}$. There was a trend toward decreased RAP during CPB in both CABG and MVR patients, although the difference did not reach statistical significance. The RAP did not change after rewarming on CPB to $36^{\circ}$ in either CABG or MVR patients. As expected, RAP did increase significantly following separation from $\mathrm{CPB}$, coincident with blood and crystalloid administraiton. Asystole occurred during CPB in most MVR patients, since hypothermia was instituted immediately after attaining full $\mathrm{CPB}$. In most CABG patients sinus rhythm was maintained during CPB until the institution of deliberate hypothermia. In both groups, rewarming on CPB was associated with resumption of electrical and mechanical activity.

\section{Anticoagulant effects on ANF concentration}

Heparin is a highly electronegative polyanionic molecule. Protamine, used to neutralize heparin following $\mathrm{CPB}$, is a basic protein. The electrostatic interaction between hepa-

TABLE II Haemodynamic variables and oesophageal temperature during cardiopulmonary bypass

\begin{tabular}{|c|c|c|c|c|c|c|c|c|}
\hline & \multicolumn{4}{|c|}{ Mitral valve replacement } & \multicolumn{4}{|c|}{ Coronary artery revascularization } \\
\hline & $R A P(m m H g)$ & $P C W P(m m H g)$ & $H R\left(\min ^{-1}\right)$ & $\operatorname{Temp}\left({ }^{\circ} \mathrm{C}\right)$ & $R A P(m m H g)$ & $P C W P(m m H g)$ & $H R\left(\min ^{-1}\right)$ & $\operatorname{Temp}\left({ }^{\circ} \mathrm{C}\right)$ \\
\hline Pre CPB & $6.9 \pm 1.3$ & $19 \pm 2$ & $92 \pm 6$ & $35.4 \pm 0.3$ & $6.0 \pm 1.1$ & $7 \pm 1$ & $70 \pm 4$ & $34.1 \pm 0.2$ \\
\hline CPB 5 min & $4.2 \pm 0.6$ & - & $18 \pm 11$ & $27.4 \pm 1.7^{*}$ & $6.6 \pm 1.2$ & - & $50 \pm 10$ & $32.2 \pm 0.3^{*}$ \\
\hline CPB $15 \mathrm{~min}$ & $3.7 \pm 0.7$ & - & $2 \pm 2$ & $27.3 \pm 0.6^{*}$ & $6.0 \pm 1.0$ & - & $52 \pm 10$ & $31.9 \pm 0.5^{*}$ \\
\hline CPB $30 \mathrm{~min}$ & $2.6 \pm 1.0$ & - & 0 & $28.3 \pm 0.8^{*}$ & $4.3 \pm 0.9$ & - & $27 \pm 10$ & $30.8 \pm 0.7^{*}$ \\
\hline $\mathrm{CPB} 60 \mathrm{~min}$ & $3.6 \pm 1.6$ & - & 0 & $29.5 \pm 0.7^{*}$ & $5.3 \pm 1.0$ & - & $10 \pm 6$ & $28.0 \pm 1.7^{*}$ \\
\hline CPB rewarm & $6.0 \pm 1.1$ & - & $47 \pm 13$ & $36.5 \pm 0.4 \dagger$ & $6.3 \pm 0.9$ & - & $71=6$ & $37.6 \pm 0.3 \dagger$ \\
\hline Off CPB & $8.4 \pm 0.7$ & $12 \pm 2$ & $104 \pm 0.2$ & $36.5 \pm 11$ & $6.6 \pm 1.2$ & $9 \pm 1$ & $82=5$ & $36.7 \pm 0.3 \dagger$ \\
\hline $60 \mathrm{~min}$ off CPB & $11.0=1.1 \dagger$ & $14 \pm 1$ & $100 \pm 4$ & $35.9 \pm 0.3 \dagger$ & $9.4 \pm 1.2 \dagger$ & $10 \pm 1$ & $99 \pm 2$ & $35.7 \pm 0.2 \dagger$ \\
\hline Skin Closure & $11.6 \pm 0.9 \dagger$ & $15 \pm 1$ & $98 \pm 6$ & $35.8 \pm 0.3$ & $11.9 \pm 1.3 \dagger$ & $14 \pm 1$ & $103 \pm 4$ & $35.6 \pm 0.3 \dagger$ \\
\hline ICU $60 \mathrm{~min}$ & $9.0 \pm 1.4 \dagger$ & $13 \pm 1$ & $91 \pm 4$ & $36.2 \pm 0.4 \dagger$ & $8.9 \pm 0.9 \dagger$ & $10 \pm 1$ & $96 \pm 3$ & $35.6 \pm 0.2 \dagger$ \\
\hline
\end{tabular}

$* P<0,05$ compared with pre $\mathrm{CPB}$

$\dagger P<0.05$ compared with CPB 60 min. 


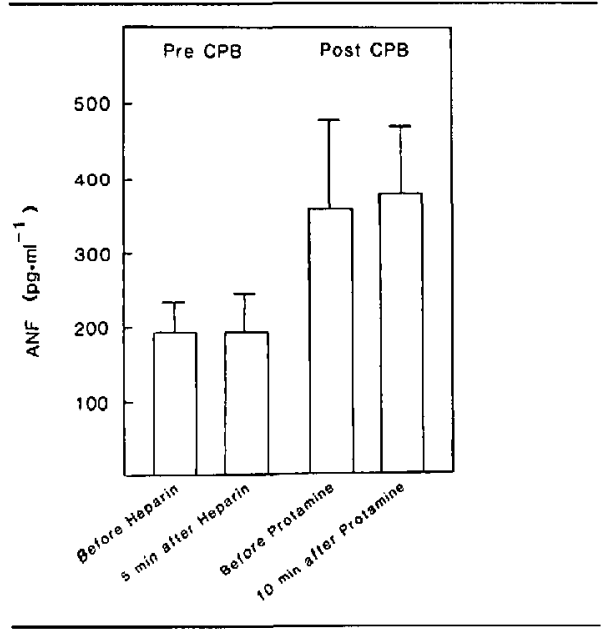

FIGURE 3 Influence of systemic heparin and protamine administration on plasma ANF concentration. The dose of heparin was 4 $\mathrm{mg} \cdot \mathrm{kg}^{-1}$ and that of protamine was $5 \mathrm{mg} \cdot \mathrm{kg}^{-1}$. Samples for analysis were obtained at the times indicated. Shown are the pooled results of 12 patients undergoing MVR or CABG. Differences between the means of paired samples were not significant.

rin and protamine results in a complex devoid of anticoagulant activity. Atrial natriuretic factor is also a strongly basic cationic peptide, owing to the presence of numerous arginine residues, ${ }^{2}$ and may therefore also form a com-
TABLE III Effect of heparin and protamine on the radioimmunoassay for ANF

\begin{tabular}{lll}
\hline Additions & & \\
\hline Heparin $\left(\mu g \cdot \mathrm{ml}^{-1}\right)$ & Protamine $\left(\mu g \cdot \mathrm{ll}^{-1}\right)$ & ANF $\left(p g \cdot \mathrm{ml}^{-1}\right)$ \\
\hline 0 & 0 & $184 \pm 21$ \\
2.5 & 0 & $197 \pm 4$ \\
5.0 & 0 & $152 \pm 14$ \\
10 & 0 & $165 \pm 21$ \\
5.0 & 6.5 & $186 \pm 12$ \\
\hline
\end{tabular}

ANF concentration was determined in blood supplemented with exogenous peptide. Results are shown as the mean $=$ SEM of five determinations. There were no statistically significant differences between any of the means.

plex with heparin. The effect of heparin and heparin plus protamine on the radioimmunoassay for ANF was therefore determined in vitro, and the results presented in Table III. Neither heparin nor protamine had any significant influence on the assay used throughout this investigation.

The in vivo influence of systemic heparin anticoagulation and protamine reversal on circulating ANF levels was also investigated, and the results presented in Figure 3. Administration of heparin ( $4 \mathrm{mg} \cdot \mathrm{kg}^{-1}$, IV) prior to CPB had no effect on plasma concentration of ANF as determined by radioimmunoassay (immunoreactive ANF). Similarly, protamine $\left(5 \mathrm{mg} \cdot \mathrm{kg}^{-1}\right.$, IV) administration following $\mathrm{CPB}$ had no effect on immunoreactive ANF levels.

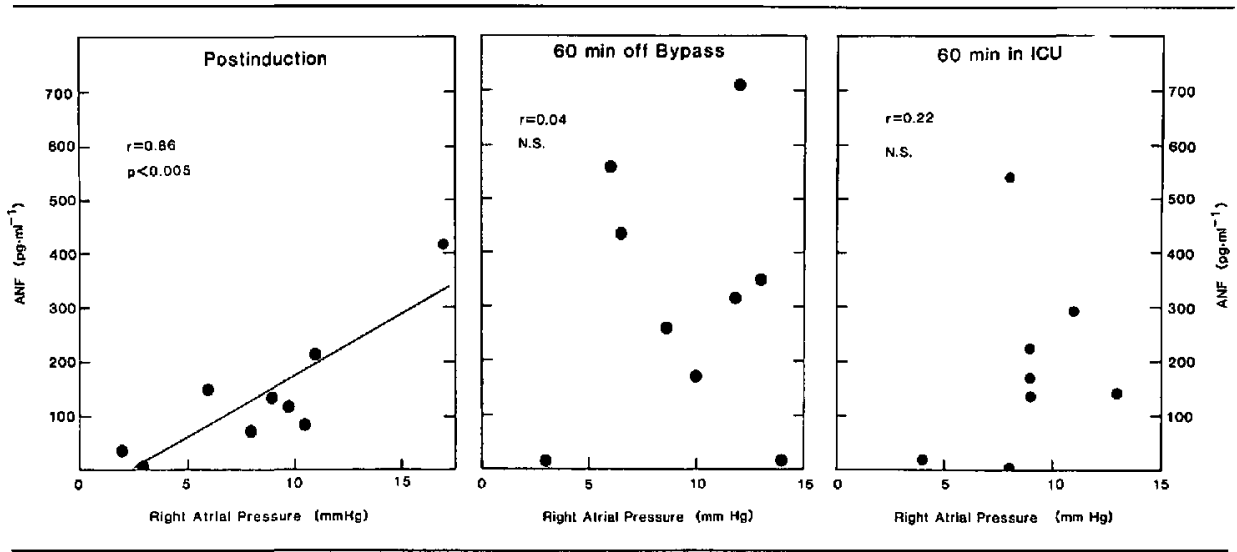

FGURE 4 Relationship between plasma ANF concentration and right atrial pressure in nine patients undergoing coronary revascularization. (left) Samples obtained after anaesthetic induction. Linear least squares analysis revealed $y=23.1 \mathrm{x}-59.8, \mathrm{r}=0.86, P<0.005$. (centre) Samples obtained 60 min after separation from cardiopulmonary bypass. There was no significant relationship between ANF levels and right atrial pressure. (right) Samples obtained $60 \mathrm{~min}$ after arrival in the Intensive Care Unit (182 $\pm 17 \mathrm{~min}$ after cardiopulmonary bypass). There was no significant relationship between ANF levels and right atrial pressure. 


\section{ANF release before and afier cardiac surgery}

Figure 4 left shows the linear relationship of arterial ANF concentration to right atrial pressure following anaesthetic induction in nine patients undergoing CABG. The relationship was described by y $=23.1 \times-59.8(r=$ $0.86, P<0.005$ ). A similar linear relationship was observed prior to anaesthetic induction ( $\mathrm{y}=24.2 \mathrm{x}$ 273.3, $\mathrm{r}=0.86, P<0.005$, data not shown). The relationship between ANF concentration and RAP after $\mathrm{CPB}$, cardioplegia-induced cardiac arrest, and cardiac surgery is presented in Figures 4 (centre) and 4 (right). Sixty minutes after CPB there was no correlation between RAP and ANF concentration. Similarly, after arrival in the Intensive Care Unit (182 $\pm 17 \mathrm{~min}$ after $\mathrm{CPB}$ ) there was no significant relationship between RAP and plasma ANF concentration. In both samples this was different from the linear relationship observed following induction of anaesthesia.

\section{Discussion}

The results presented suggest a specific influence of mitral valve disease on ANF concentration, and this is in agreement with previous observations. ${ }^{12,24}$ The mean baseline ANF levels in patients undergoing MVR were higher than those undergoing $C A B G$ despite equivalent RAP. However, ANF levels in MVR patients were associated with higher pulmonary artery and PCW pressures. The highest ANF concentrations were found in patients with mitral stenosis. Plasma ANF levels were lower after MVR compared with preoperative values. Similarly, PCWP was decreased compared with preoperative PCWP while RAP was unchanged. Thus replacement of a diseased mitral valve resulted in normalization of PCWP, associated with a postoperative decline in ANF concentration.

Results of the present investigation demonstrate that plasma levels of ANF changed significantly during surgery for coronary artery revascularization and mitral valve replacement in the patient population studied. Initiation of hypothermic cardiopulmonary bypass was associated with a progressive decrease in plasma ANF concentrations in patients undergoing either $C A B G$ or MVR. After 60 min of CPB, ANF levels declined to 60 per cent (CABG) and four per cent (MVR) of the pre-CPB values. Rewarming during $\mathrm{CPB}$ and fluid administration in the immediate post-CPB period were associated with peptide concentrations significantly greater than those during $\mathrm{CPB}$, which often exceeded baseline preinduction values. In contrast to the observed decline in CPB ANF levels, preliminary reports of similar studies have indicated variable results. ANF concentrations during CPB have been described as unchanged, ${ }^{25,26}$ decreased, ${ }^{27}$ or even increased. ${ }^{28}$ Patient characteristics, technical considerations in surgery or CPB may underlie such differences, but definitive comparisons cannot be made from these preliminary reports.

The observed changes in ANF concentration during and after CPB may be related to alterations in heart rate, atrial pressure, and/or body temperature. Decreases in CPB ANF concentrations during CABG and MVR paralleled the decline in heart rate. Resumption of atrial contraction after rewarming was associated with increased ANF concentration. Previous studies have shown that plasma ANF concentration is directly related to heart rate, ${ }^{12}$ and that changes in heart rate elicit a proportional change in ANF release. ${ }^{18,19}$

The plasma ANF concentrations during and after CPB may also be related to atrial pressure. Atrial distension is a potent stimulus for ANF release, and numerous investigations have shown that ANF release and circulating ANF concentrations are proportional to right or left atrial pressure. ${ }^{12,13,29}$ Specific decreases in RAP were followed rapidly by a fall in ANF plasma levels. ${ }^{30-32}$ In the present investigation, there was a trend towards lower RAP during CPB. Following bypass, elevated RAP due to rapid fluid administration was followed by an increase in plasma peptide levels.

Body temperature is the third factor potentially influencing ANF levels during and after CPB. Peptide levels during $C A B G$ did not decrease significantly until deliberate hypothermia $\left(28^{\circ} \mathrm{C}\right)$, while rapid cooling to $<28^{\circ} \mathrm{C}$ during MVR was followed by a rapid decline in ANF concentration. Rewarming to $36-37^{\circ} \mathrm{C}$ during $\mathrm{CPB}$ was followed by elevated ANF levels in both MVR and CABG patients. In blood samples obtained immediately after rewarming but before return of sinus rhythm or atrial filling, ANF concentrations were also increased (data not shown), suggesting a contribution of temperature apart from heart rate or atrial pressure. Increased ANF plasma levels during rewarming have also been reported by others. ${ }^{25-28}$ These observations are consistent with those of Bilder et al., who demonstrated a specific influence of temperature on ANF release. ${ }^{17}$ Since the decline in heart rate paralleled that of temperature, the data presented do not allow determination of the relative contributions of heart rate and temperature to the observed changes in ANF levels during CPB.

The greater decline of CPB ANF concentrations in MVR compared to CABG may be due to the higher initial PCWP and ANF levels in MVR patients, differences in heart rate and temperature declines during CPB (as discussed above), or use of dual vena cava cannulae and an open atrial surgical approach for MVR versus a single two-stage atrial cannula for CABG. Although this latter explanation is less likely, since the different surgical approaches resulted in similar changes in atrial pressures during $\mathrm{CPB}$, the data at present do not allow a more definitive interpretation. 
There exist two potential methodological limitations of the present investigation. First, haemodilution from crystalloid priming of the CPB circuit might dilute circulating ANF, thereby lowering plasma concentrations. In six patients arbitrarily selected from the 16 studied, total plasma protein was measured in addition to immunoreactive ANF. Total protein decreased from 5.0 $\pm 0.5 \mathrm{~g} \cdot \mathrm{dl}^{-1}$ (mean $\pm \mathrm{SEM}$ ) in pre-CPB samples to 3.2 $\pm 0.2 \mathrm{~g} \cdot \mathrm{dl}^{-1}$ in the CPB 5-min sample, consistent with haemodilution (25-35 per cent) from $\mathrm{CPB}$ pump prime $\left(25 \mathrm{cc} \cdot \mathrm{kg}^{-1}\right)$. No further haemodilution occurred during CPB (total protein $3.3 \pm 0.3,4.0 \pm 0.3$ and $4.0 \pm 0.3 \mathrm{~g}$. $\mathrm{dl}^{-1}$ after 15,30 and $60 \mathrm{~min}$ of $\mathrm{CPB}$, respectively). Thus diminished ANF concentrations after 15, 30 and $60 \mathrm{~min}$ CPB were not the result of haemodilution. Similarly, increased plasma ANF levels after CPB were not the result of haemoconcentration since plasma protein concentration was unchanged after CPB $\left(3.8 \pm 0.2 \mathrm{~g} \cdot \mathrm{dl}^{-1}\right)$. The second potential limitation was the change from radial artery blood sampling during CPB. Blood could not be aspirated reliably from the radial artery cannula during CPB. Blood during CPB was therefore obtained from the venous return limb of the bypass circuit. Venous blood was sampled because oxygenated CPB blood is retained in a reservoir before return to the patient which prevents accurate sample timing. Comparison of the pre-CPB sample with the CPB 5-min sample allowed evaluation of sampling site effects (as well as haemodilution effects; see above). In both MVR and CABG patients there was no significant difference in ANF concentration between the pre-CPB and CPB 5-min samples. Furthermore, all samples during CPB were obtained from the same site, and decreases in ANF concentration on CPB were significant when compared with either the pre-CPB or the CPB 5-min sample. Thus effects of different sampling sites were considered negligible. These methodological considerations therefore do not represent significant study limitations and do not alter the conclusion that plasma ANF levels were altered during and after hypothermic CPB.

Systemic heparinization before CPB and neutralization of heparin after CPB had no effect on circulating ANF concentrations as measured by radioimmunoassay. Although heparin did not alter the ANF radioassay or plasma levels of immunoreactive ANF, one report suggests that heparin may diminish ANF bioactivity. ${ }^{33}$ Thus, further studies are needed to determine the influence of heparin and protamine on the bioactivity of human ANF during CPB.

It is now well established that the heart is an endocrine organ: ANF is released proportionately in response to atrial distension. In patients undergoing $C A B G$, the ANF concentration at baseline and following anaesthetic induction was linearly related to RAP. This linear relationship was similar to that observed previously. ${ }^{12.13}$ However, following cardioplegic arrest and CPB there was no significant relationship between RAP and ANF plasma concentration. The dissociation between RAP and ANF concentration persisted for at least $3 \mathrm{hr}$ after separation from CPB. Conventional hypothermic cardioplegia inadequately protects the right atrium, resulting in ischaemia and marked ischaemic contractile dysfunction after CPB.$^{34}$ Atrial ischaemia may also be responsible for the altered relationship between atrial pressure and ANF levels after CPB and cardiac surgery.

Results presented here represent an initial description of ANF levels during cardiac surgery. The endocrine response to CBP has been previously described, consisting of increases in catecholamine, renin, $A D H$, and cortisol concentrations. ${ }^{35,36}$ Decreases in ANF levels during CBP are in contrast to increases in these 'stress' hormones. Atrial natriuretic factor inhibits secretion of renin, ADH and aldosterone, and changes in plasma renin-aldosterone concentrations are inversely proportional to changes in plasma ANF concentration. ${ }^{32,37}$ The relationship between ANF and these other hormones during $\mathrm{CPB}$ merits further investigation. Urine output and sodium excretion have been positively correlated with plasma ANF levels. ${ }^{30.37}$ The use of mannitol during CPB precluded measurement of urine output and sodium excretion in the present investigation, and the relationship between ANF and renal function during $\mathrm{CPB}$ also requires further study.

In summary, plasma ANF concentrations declined during nonpulsatile hypothermic cardiopulmonary bypass in patients undergoing CABG or MVR. In addition, the proportional circulation of ANF in response to atrial pressure was altered following $\mathrm{CPB}$ in CABG patients.

\section{Acknowledgements}

The authors are grateful to Linda Laposky and Sonja Kapitan for their tireless and excellent technical assistance. Synthetic ANF was the generous gift of Dr. R.L. Nutt of Merck, Sharpe and Dohme Research Laboratories. Dr. Charles Buffington provided helpful comments on the manuscript. Susan Perkins and Mary Lee typed the manuscript.

\section{References}

1 de Bold AJ, Borenstein HB, Veress AT, Sonnenberg $H$. A rapid and potent natriuretic response to intravenous injection of atrial myocardial extract in rats. Life Sci 1981; 28: 89-94.

2 Cantin $M$, Genest $J$. The heart and the atrial natriuretic factor. Endocrine Reviews 1985; 6: 107-27.

3 Ballermann $B J$, Brenner BM. Role of atrial peptides in body fluid homeostasis. Circ Res 1986; 58: 619-30. 
4 Burnett JC, Opgenorth TJ, Granger JP. The renal action of atrial natriuretic peptide during control of glomerular filtration. Kidney Int 1986; 30: 16-9.

5 Weidmann P, Hasler L, Gnadinger MP et al. Blood levels and renal effects of atrial natriuretic peptide in normal man. J Clin Invest 1986; 77: 734-42.

6 Anderson JV, Struthers AD, Payne NN, Slater JDH, Bloom $S R$. Atrial natriuretic peptide inhibits the response to angiotensin II in man. Clin Sci 1986; 70: 507-12.

7 Cody RJ, Atlas SA, Laragh JH et al. Atrial natriuretic factor in normal subjects and chronic heart failure patients. Plasma levels and renal, hormonal, and hemodynamic repsonses to peptide infusion. J Clin Invest 1986; 78: 1362-74.

8 Fujio $N$, Ohashi $M$, Nawata $H$ et al. Human atrial natriuretic polypeptide reduces the plasma arginine vasopressin concentration in human subjects. Clin Endocrinol 1986; 25: 181-7.

9 Dillingham MA, Anderson RJ. Inhibition of vasopressin action by atrial natriuretic factor. Science 1986; 231 : 1572-3.

10 Ledsome JR, Wilson N, Rankin AJ, Courneya CA. Time course of release of atrial natriuretic peptide in the anesthetized dog. Can J Physiol Pharmacol 1986; 64: 1017-22.

11 Richards AM, Nicholls MG, lkram $H$, Webster MWI, Yandie TG, Espiner EA. Renal, haemodynamic, and hormonal effects of human alpha atrial natriuretic peptide in healthy volunteers. Lancet 1985; 1 : 545-9.

12 Bates ER, Shenker Y, Grekin RJ. The relationship between plasma levels of immunoreactive atrial natriuretic hormone and hemodynamic function in man. Circulation 1986; 73: 1155-61.

13 Rodeheffer RJ, Tanaka I, Imada T, Hollister AS, Robertson $D$, Inagomi $T$. Atrial pressure and secretion of atrial natriuretic factor into the human central circulation. J Am Coll Cardiol 1986; 8: 18-26.

14 Garcia R, Thibault G, Cantin M, GutkowskaJ. Role of the right and left atrium on UNaV and ANF release during volume expansion and reduction. Hypertension 1986; 8: 826 .

15 Hollister AS, Byrd BF, Potrs JR, Parrish CK, Imada T, Inagami $T$. Plasma atrial natriuretic factor levels correlate with right atrial pressure, echocardiographic dimensions and calculated wall tension in human subjects. Circulation 1986; 74: 11-21

16 Schiebinger RJ, Linden J. The influence of resting tension on immunoreactive atrial natriuretic peptide secretion by rat atria superfused in vitro. Circ Res 1986; 59: 105-9.

17 Bilder GE. Schofield TL, Blaine EH. Release of atrial natriuretic factor. Effects of repetitive stretch and temperature. Am J Physiol 1986; 251: F817-21.

18 Crozier IG, Nicholls G, Ikram H, Espiner EA, Yandle TG,
Jans $S$. Atrial natriuretic peptide in humans. Production and clearance by various tissues. Hypertension 1986;8 (suppl. II): 11-5.

19 Rankin AJ, Courneya CA, Wilson N, Ledsome JR. Tachycardia releases atrial natriuretic peptide in the anesthetized rat. Life Sci 1986; 38: 1951-7.

20 Horky K, Gutkowska J, Garcia R, Thibault G, Genest J. Cantin $M$. Effect of different anesthetics on immunoreactive atrial natriuretic factor concentrations in rat plasma. Biochem Biophys Res Commun 1985; 129: 651-7.

21 Sugawara A, Nakao K, Morii N et al. o-Human atrial natriuretic polypeptide is released from the heart and circulates in the body. Biochem Biophys Res Commun 1985; 129: 439-46.

22 Zar JH. Biostatistical analysis. Englewood Cliffs, NJ, Prentice-Hall, Inc., 1984.

23 Schiffrin EL, Gutkowska J, Kuchel O, Cantin M, Genest J. Plasma concentration of atrial natriuretic factor in a patient with paroxysmal atrial tachycardia. New Engl J Med 1985; 312: 1196-7.

24 Yoshimi $H$, Inoue I, Hirata $Y$ et al. Atrial natriuretic peptide secretion in mitral stenosis. Am J Cardiol 1987; 60: 396-7.

25 Flezzani P, Mcintyre RW, Xuan $Y T$, Su YF, Leslie JB, Watkins WD. Atrial natriuretic peptide during cardiac surgery: a comparison of valvular heart disease and ischemic heart disease. Anesthesiology 1986; 65: A511.

26 Hedner J, Towle A, Saltzman L et al. Atrial natriuretic factor in plasma of patients undergoing cardiopulmonary bypass surgery. Anesthesiology 1986; 65: A509.

27 Sugawara A, Nakao K, Morii $N$ et al. Significance of $\alpha$-human atrial natriuretic polypeptide as a hormone in humans, Hypertension 1986; 8(Suppl. II): 151-5.

28 Greeley WJ. Leslie JB, Su M. Davis DP, Xuan T, Watkins $W D$. Plasma atrial natriuretic peptide release during pediatric cardiovascular anaesthesia and surgery. Anesthesiology 1986; 65: A414.

29 Ruskoaho $H$, Tholken $H$, Lang $R E$. Increase in atrial pressure releases atrial natriuretic peptide from isolated perfused rat hearts. Pflugers Arch 1986; 407: 170-4.

30 Hollister AS, Tanaka I, Imada $T$ et al. Sodium loading and posture modulate human atrial natriuretic factor plasma levels. Hypertension 1986; 8 (Suppl. II): 106-11.

31 Ogihara T, Shima J, Hara H, Kumahara $Y$, Kangawa $K$, Matsuo $H$. Changes in human plasma atrial natriuretic polypeptide concentration in normal subjects during passive leg raising and whole-body tilting. Clin Sci 1986; 71: $147-50$.

32 JacobL, Payen D, Teillac $P$ et al. Evidence for right atrial pressure control of plasma atrial natriuretic factor during lumbar epidural anesthesia and lower body positive pressure. Anesthesiology 1986; 65: A222. 
33 Wei Y, Holmberg SW, Leahy $K M$, Olins PO, Devine CS, Needleman $P$. Heparin interferes with the biological effectiveness of atriopeptin. Hypertension 1987; 9 ; 607-10.

34 Spence PA, Peniston CM, Weisel RD, Jabr AK, Yap V, Salerno TA. Is atrial function affected by conventional cardioplegic arrest? J Surg Res 1985; 38: 509-14.

35 Philbin $D M$. Endocrine response to cardiopulmonary bypass. Mt Sinai J Med 1985; 52: 508-10.

36 Reeves $J G$. Adrenergic response to cardiopulmonary bypass. Mt Sinai J Med 1985; 52: 511-5.

37 Shenker Y, Sider RS, Ostafin EA, Grekin RJ. Plasma levels of immunoreactive atrial natriuretic factor in healthy subjects and in patients with edema. J Clin Invest 1985; $76: 1684-7$.

\section{Résumé}

En réponse a la distension de l'oreillene, le cour libère un peptide, le facteur natriurétique de l' oreillette (ANF), qui induir diurèse et vasodilatation, diminue la tension artérielle et inhibe La libération de la rénine, de l'aldostésterone et de l'hormone anti-diurétique. Pour évaluer l'impact de la circulation extra-corporelle $(C E C)$ et de la chirurgie cardiaque sur la sécrétion d'ANF, nous en avons mesuré la concentration plasmatique ([ANF]) lors de revascularisations coronariennes (pontage) et de remplacements de la valve mitrale (valvuloplastie). Dans les deux types d'interventions, les niveaux $d^{\prime} A N F$, inchangés après l'induction anesthésique, diminuèrent significativement avec la CEC (temp. $28^{\circ} \mathrm{C}$ ). Après 60 minutes sous $C E C$, la [ANF] était passé de $512 \pm 132 d 20 \pm 6 \mathrm{pg} \cdot \mathrm{ml}^{-1}(P \leq$ $0.05)$ dans le groupe * valvuloplastie $»$ et de $178 \pm 41$ a $110 \pm$ $48 \mathrm{pg} \cdot \mathrm{ml}^{-1}(P \leq 0.05)$ dans le groupe "pontage ». La [ANF] augmentait pendant le réchaufferment sous CEC mais était indifférente dl' anticoagulation par héparine et d̀ son antagoniste, la protamine. Dans le groupe "pontage», nous avons observé une relarion linéaire entre [ANF] et la pression de loreillette droite avant $C E C(r=0.86, P \leq 0.05)$ mais, cette relation ne tenait plus, une heure et trois heures post-CEC. Il semble donc qu'il y ait diminution de la concentration plasmatique d'ANF pendant la CEC hyporhermique et qu'en plus il y ait perturbation du couple ANF-pression de l'oreillette après la chirurgie cardiaque. 